\title{
Letter
}

\section{Spawning site selection by Eurasian perch (Perca fluviatilis L.) in relation to temperature and wave exposure}

Probst WN, Stoll S, Hofmann H, Fischer P, Eckmann R. Spawning site selection by Eurasian perch (Perca fluviatilis L.) in relation to temperature and wave exposure.

Ecology of Freshwater Fish 2009: 18: 1-7. (C) 2008 The Authors. Journal compilation (C) 2008 Blackwell Munksgaard

Abstract - The selection of spawning depth by Eurasian perch Perca fluviatilis was investigated in an experiment using artificial substrata in Lake Constance during the spawning season of 2007. The experiment compared spawning behaviour at substrata between 0.5 and $15 \mathrm{~m}$ depth at two sites exposed to different regimes of ship-generated wave action. The total abundance of egg ribbons did not differ significantly between the two sites, but the preferred spawning depth was deeper at the wave exposed site $(5 \mathrm{~m})$ compared to the sheltered site $(2 \mathrm{~m})$. While water temperatures could not account for the observations, differences in wave exposure may explain the different spawning depth preferences. At both sites, large egg ribbons were generally found in deeper water, and large egg ribbons occurred more frequently at the sheltered site. Because the egg ribbons of perch are likely to have a size-dependent susceptibility to hydrodynamic stress, large females may be expected to select deeper spawning locations where the effects of surface waves are considerably attenuated.

\author{
W. N. Probst ${ }^{1}$, S. Stoll', \\ H. Hofmann ${ }^{1}$, P. Fischer ${ }^{2}$, \\ R. Eckmann ${ }^{1}$ \\ ${ }^{1}$ Limnological Institute, University of Konstanz, \\ Konstanz, Germany, ${ }^{2}$ Alfred-Wegener-Institute \\ für Polar and Marine Research, Biologische \\ Anstalt Helgoland, Helgoland, Germany
}

Key words: egg ribbon; substrate; spawning depth; hydrodynamics; Lake Constance

Wolfgang Nikolaus Probst, Limnological Institute, University of Konstanz, 78457 Konstanz, Germany; e-mail: wolfgang.probst@ uni-konstanz.de

Accepted for publication June 26, 2008

\section{Introduction}

The littoral zones of lakes are important spawning locations for many freshwater fish species. The substrata upon which eggs are deposited may vary considerably in composition and structure, with features including macrophytes, cobbles and stones, submersed woody debris and anthropogenic structures (Gerstmeier \& Romig 2003; Winfield 2004). Eggs spawned in the littoral zone benefit from a number of advantages, because eggs experience warmer water temperatures compared to pelagic or profundal habitats (Huff et al. 2004), can attach better to substrate with low periphyton cover (Gafny et al. 1992) and larvae/juvenile fish find refuge from predators (Fischer \& Eckmann 1997; Stoll et al. 2008). Consequently, spawning in lake littorals is a common strategy among many fish species. In central Europe, littoral spawners include many cyprinid species such as bleak Alburnus alburnus, roach Rutilus rutilus and bream Abramis brama and as well as pike Esox lucius and Eurasian perch Perca fluviatilis (Gerstmeier \& Romig 2003).

Eurasian perch spawn during April and May, when water temperatures rise above $10{ }^{\circ} \mathrm{C}$ (Treasurer 1988; Wang \& Eckmann 1994; Gillet \& Dubois 2007). The eggs are embedded into a gelatinous, ribbon-like structure, which is deposited by the female in a single spawning event. Spawning females typically favour substrata in which eggs can be deposited amongst complex structures such as woody debris or macrophytes (Gillet \& Dubois 2007), but newly spawned egg ribbons can also be found on substrata comprising only sandy or muddy sediment (W. N. Probst, personal observation).

In addition to substratum structure, other factors known to influence spawning site selection in perch include temperature, UV-radiation and hydrodynamic stress. Temperature influences the onset of spawning, 
which is strongly related to surface temperatures between 10 and $14{ }^{\circ} \mathrm{C}$ (Gillet et al. 1995; Gillet \& Dubois 2007). The temperature controlled onset of spawning provides an adaptation to the optimal egg survival, hatching success and swim-up of perch larvae (Wang 1994). Hydrodynamic stress caused by wave-generated currents can damage eggs directly and may also dislodge attached eggs and remove them to a less favourable location. Both scenarios may result in severe rates of mortality (Rupp 1965). Local wind regimes during the spawning season may also govern the thermal regime within spawning habitats and have been shown to influence larval survival in North American yellow perch Perca flavescens (Aalto \& Newsome 1993). UV-radiation can inflict high mortalities on eggs of yellow perch, which have been found to favour shallower spawning sites in lakes in which high dissolved organic carbon concentrations result in greater turbidity (Williamson et al. 1997; Huff et al. 2004).

This study investigates the influence of hydrodynamic forces on spawning site selection in Eurasian perch. The depth distribution of perch egg ribbons was compared between two experimental sites in which substratum type was artificially standardised, but wave exposure differed. We hypothesised that egg ribbons would be found at greater depths at the site with frequent and high-amplitude wave events than at the sheltered site. Furthermore, if spawning depth was affected by hydrodynamic forces, we expected egg ribbon size to be an additional factor in depth distribution, because large egg ribbons should be more prone to wave dislodgment and damage than smaller ribbons.

\section{Materials and methods}

\section{Study sites}

Upper Lake Constance, situated on the borders of Germany, Switzerland and Austria, is the second largest pre-alpine lake in Europe. It is a deep oligotrophic, warm-monomictic lake with a maximum depth of $254 \mathrm{~m}$ and a surface area of $473 \mathrm{~km}^{2}$ (Stoll et al. 2008). In summer and spring, the lake is popular with tourists and subject to heavy boat traffic in the form of ferries, passenger boats and other pleasure craft (Hofmann et al. 2008).

The experiments were conducted at two sites in the eastern part of Überlinger See, a fjord-like bay in the western basin of Upper Lake Constance. The two sites, in the following named Mainau (MAI) and Littoral Garden (LIT), experience different wave exposure, but have similar topography with a shallow 50-70 m wide littoral fringe extending to about $2 \mathrm{~m}$ depth, from where the lake bottom slopes downward at an angle of approximately $40^{\circ}$. MAI is located on the sheltered northern shore of the island of Mainau, while LIT lies on the lake shore between Konstanz-Egg and Konstanz-Staad and is subject to frequent ship waves generated by car ferries and passenger cruise ships (Hofmann et al. 2008).

\section{Depth preference}

To test the preferred spawning depth of perch in the absence of substratum influences, artificial substrates were brought into the lake at the depth range where perch spawning had been observed in previous years. At each experimental site, a total of 18 spruce trunks (with twigs) were installed on 24 April 2007. The trunks were trimmed to a height of approximately $1.2 \mathrm{~m}$ and a width of approximately $0.8 \mathrm{~m}$ and introduced in sets of three at each of six depths; 0.5, $1,2,5,10$ and $15 \mathrm{~m}$. Each trunk was weighted with a $3 \mathrm{~kg}$ paving slab and pinned to the lake bottom with 40 -cm-long iron hooks. The three trunks at each depth were spaced approximately $3 \mathrm{~m}$ apart, thus ensuring that each trunk was far enough from its neighbours to be considered an independent replicate, but still easy for divers to locate on subsequent occasions.

SCUBA divers visited the sites weekly between 2 and 16 May 2007 to record the abundance and size distribution of perch egg ribbons, thus providing data from 3 weeks (week 1 = 24 April-2 May 2007, week $2=2-10$ May 2007, week $3=10-16$ May 2007). The divers counted the number of egg ribbons on each spruce trunk and measured the width at the middle of each ribbon. Once counted, all egg ribbons were removed from the spruce trunks to ensure that no ribbon was counted more than once on consecutive sampling dates.

\section{Temperature and wave exposure}

Water temperatures were recorded at three depths at each site using logging devices (ONSET, Bourne, MA, USA) attached to spruce trunks at $0.5,5$ and $15 \mathrm{~m}$. The temperature was logged with a precision of $0.1{ }^{\circ} \mathrm{C}$ every $15 \mathrm{~min}$ over the entire duration of the experiment.

To establish the relative degree of wave exposure at each site, surface wave fields were measured using a pressure sensor between 2 and 10 May 2007, a period covering peak perch spawning when no strong wind events occurred. Thus the wave velocities recorded at both sites reflected only the impact of ship-induced waves, which may be considered representative of other weeks of perch spawning because the commercial boat traffic in Lake Constance follows a very regular schedule during the summer season. The pressure sensor has a full-scale range of $7 \mathrm{~m}$, an accuracy of $0.1 \mathrm{mbar}$, 
and was deployed at a water depth of $2 \mathrm{~m}$. Pressure measurements were made at $16 \mathrm{~Hz}$. Wave parameters were calculated for burst intervals of 1024 $(\sim 1.1 \mathrm{~min})$ samples using the procedure described in Hofmann et al. (2008).

Maximum near-bottom current velocity $u_{\max }$ $\left(\mathrm{m} \cdot \mathrm{s}^{-1}\right)$ is a parameter that characterises the influence of surface waves on shearing forces close to the bottom, where perch eggs are deposited (Brown et al. 2005; Kundu \& Cohen 2008). $U_{\max }$ was calculated for each burst interval and water depth $(0.5,1,2,5,10$ and $15 \mathrm{~m}$ ) by using the appropriate dispersion relation. Based on site specific $u_{\max }$ time series, overall daily mean values and mean values of the upper $10 \%$ of $u_{\max }$ with their standard deviation were calculated for all water depths.

\section{Statistical analysis}

The influence of spawning week, experiment site and depth on the abundance of egg ribbons was tested with a full-factorial three-way ANOVA. The abundance data of egg ribbons per spruce tree was sqrt $(x+0.5)$ transformed to achieve variance homogeneity.

A general linear model (GLM) was applied to analyse the influence of spawning week, experimental site and depth on the observed width of egg ribbons. In the GLM, depth was considered as a continuous factor, because egg ribbons were not found at all depths, thus ANOVA was not applicable due to imbalanced cell design.

Differences in average diel water temperatures between MAI and LIT at 0.5, 5 and $15 \mathrm{~m}$ depth were tested with a GLM to examine potential influences of experiment site, depth (categorical factors) and date (continuous factor).

The differences in daily mean $u_{\max }$ were tested with a full-factorial two-way ANOVA, in which experiment site and depth were used as predictive factors. The data were log-transformed to achieve homogeneity of variances. Furthermore, because $<4 \%$ of perch egg ribbons were found at $15 \mathrm{~m}$ depth and no egg ribbons were found at $0.5 \mathrm{~m}$ depth, these depth layers were considered as negligible and were also excluded from the analysis. Values for $u_{\max }$ were so variable at $0.5 \mathrm{~m}$ depth, that the homogeneity of variances could not be achieved when these data were included.

\section{Results}

\section{Substrate and depth preference}

The spawning season of perch commenced by the end of April 2007, with the first egg ribbon in the lake littoral zone reported on 24 April 2007. A total of 296 egg ribbons were counted and measured on the spruce trunks between 2 and 16 May 2007. Peak spawning occurred in week 2 of the experiment. In week 3 , spawning activity was reduced and only 20 egg ribbons were recorded in the last census (Fig. 1).

The full factorial three-way ANOVA indicated that the total egg ribbon abundance did not differ between the sites MAI and LIT (Table 1). However, egg ribbon abundance was affected by the week of spawning and depth and there were significant interactions between experiment site*depth and week*depth. The interaction between site and depth resulted from the fact that peak ribbon abundance occurred at $2 \mathrm{~m}$ depth at MAI and at $5 \mathrm{~m}$ depth at LIT (Fig. 1). The interaction between week*depth resulted from changes in the depth distribution of egg ribbons from week to week. No egg ribbons were found above $1 \mathrm{~m}$ at either site and only 11 egg ribbons $(=4 \%)$ were found deeper than $10 \mathrm{~m}$ (Fig. 1). The total abundance of egg ribbons did not differ between the sites MAI and LIT (Table 1).

The width of observed egg ribbons differed significantly from week to week, between sites and also with depth (Table 1). Wider egg ribbons were found later in the spawning season and in deeper water. The egg ribbons found at MAI were generally wider than those from LIT (mean egg ribbon width MAI: $4.266 \pm 0.232 \mathrm{~cm}$ SE; LIT: $2.655 \pm 0.204 \mathrm{~cm} \mathrm{SE}$ ). The results suggest that larger females tend to spawn later and that they favour deeper water and more sheltered habitats than smaller conspecifics. The interaction between week and depth indicates that in week 1 the largest egg ribbons were found at $1 \mathrm{~m}$ depth, whereas by week 3 the largest egg ribbons were found at $10 \mathrm{~m}$ depth (Fig. 1).

\section{Temperatures and hydrodynamic stress}

Water temperatures did not differ significantly between MAI and LIT (GLM, d.f. $=1, F=2.245$, $P=0.136$ ), but were significantly affected by date and by depth (GLM, date: d.f. $=1, F=32.421$, $P<0.001$; depth: d.f. $=2, F=202.591, P<0.001$, Fig. 2). There was a drop in water temperatures during the week of peak spawning (between 2 and 10 May 2007), which was detectable at 0.5 and $5 \mathrm{~m}$ depth. At $15 \mathrm{~m}$, the water temperatures rose to $10{ }^{\circ} \mathrm{C}$ at MAI by the end of April without appearing to stimulate perch spawning, then dropped again to $8{ }^{\circ} \mathrm{C}$ until the last week of spawning.

Daily mean $u_{\max }$ during the week of peak spawning was generally lower at MAI than at LIT (two-way ANOVA, d.f. $=1, F=113.477, P<0.001$; Fig. 3a). Daily mean $u_{\max }$ also varied between depths (two-way ANOVA, d.f. $=3, F=168.129, P<0.001$ ), but were 
Probst et al.

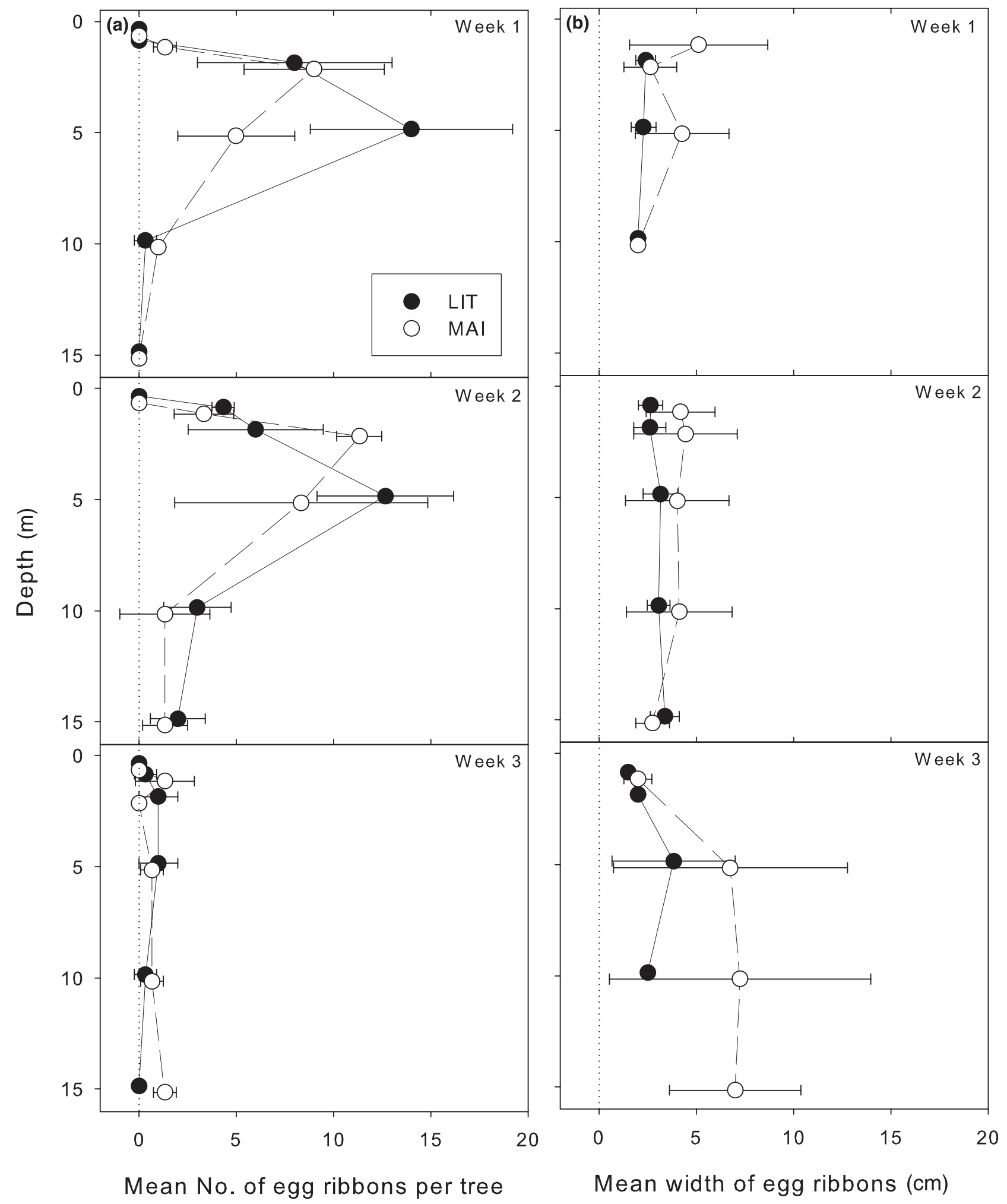

Fig. 1. Differences in egg ribbon abundance and width at sites MAI and LIT in 3 weeks of perch spawning. (a) Mean abundance of egg ribbons $( \pm \mathrm{SD})$ in relation to depth. (b) Mean width of egg ribbons $( \pm \mathrm{SD})$.

similar at the main spawning depths of both sites $\left(0.0115 \mathrm{~m} \cdot \mathrm{s}^{-1}\right.$ at $2 \mathrm{~m}$ depth at MAI; $0.0079 \mathrm{~m} \cdot \mathrm{s}^{-1}$ at $5 \mathrm{~m}$ depth at LIT, Student-Newman-Keuls test, d.f. $=64, P>0.05)$. Depth- and site-related differences in $u_{\max }$ were also apparent when considering the mean of the upper most $10 \%$ of $u_{\max }$ (Fig. 3a,b). 
Table 1. Results of full factorial three-way anova and GLM for egg ribbon abundance per spruce trunk (total $N=108$ ) and width of egg ribbons (total $N=296)$.

\begin{tabular}{llrrr}
\hline Variable & Factor & d.f. & F-value & $P$-value \\
\hline Abundance & Week & 2 & 42.926 & $<\mathbf{0 . 0 0 1}$ \\
& Site & 1 & 0.058 & 0.811 \\
& Depth & 5 & 43.616 & $<\mathbf{0 . 0 0 1}$ \\
& Week ${ }^{*}$ Site & 2 & 0.557 & 0.575 \\
& Week Depth & 10 & 10.044 & $<\mathbf{0 . 0 0 1}$ \\
& Site ${ }^{*}$ Depth & 5 & 3.530 & $\mathbf{0 . 0 0 7}$ \\
\multirow{6}{*}{ Width } & Week ${ }^{*}$ Site ${ }^{*}$ Depth & 10 & 2.224 & $\mathbf{0 . 0 2 6}$ \\
& Week & 2 & 3.979 & $\mathbf{0 . 0 2 0}$ \\
& Site & 1 & 12.043 & $<\mathbf{0 . 0 0 1}$ \\
& Depth & 1 & 6.097 & $\mathbf{0 . 0 1 4}$ \\
& Week* Site & 2 & 0.297 & 0.743 \\
& Week ${ }^{*}$ Depth & 2 & 7.382 & $<\mathbf{0 . 0 0 1}$ \\
& Site ${ }^{*}$ Depth & 1 & 1.432 & 0.232 \\
\hline
\end{tabular}

Week indicates the week of spawning, site refers to two experiment locations of MAI and LIT and depth refers to the six water depths $(0.5,1,2,5,10$ and $15 \mathrm{~m})$. The third degree-interaction Week ${ }^{\star}$ Site ${ }^{\star}$ Depth was excluded from the GLM analysis on egg ribbon width, because it was not significant. d.f., degrees of freedom; $F$, value of F-statistic; $P$, level of significance, which was considered as significant and printed in bold italic when $P<0.05$.

\section{Discussion}

The present results demonstrate the influence of hydrodynamic stress on the distribution of egg ribbons. The environmental influences at the site of egg incubation may have severe impacts on the survival off eggs (Sandström et al. 1997) and thus it can be assumed, that female perch select favourable sites for spawning.

Among factors influencing the spawning behaviour and site selectivity of perch, temperature is the best studied. However, since mean diel water temperatures did not significantly differ between the two sites in this study, the differing depths of peak egg ribbon abundance in week 2 cannot be interpreted as a compensative behaviour of perch for different water temperatures. Instead, the possibility that the observed differences in egg ribbon abundances result from differential survival rates should not be discounted. Egg ribbons laid at $2 \mathrm{~m}$ depth at LIT may have been dislodged by the boat waves, leading to an underestimated number of observed egg ribbons in the subsequent census. However, the similarity in total numbers of spawned egg ribbons at MAI and LIT suggests that the observed differences in spawning depth rather reflect a selection behaviour of perch than differential survival during egg incubation.

The delayed spawning of large female perch and the apparent preference of large females for deeper areas of the littoral zone recorded in this study are in accordance with previous observations in Lake Geneva (Gillet \& Dubois 2007). Accordingly, in our study, large females spawned deeper and more frequently during week 3 , when the water tempera-

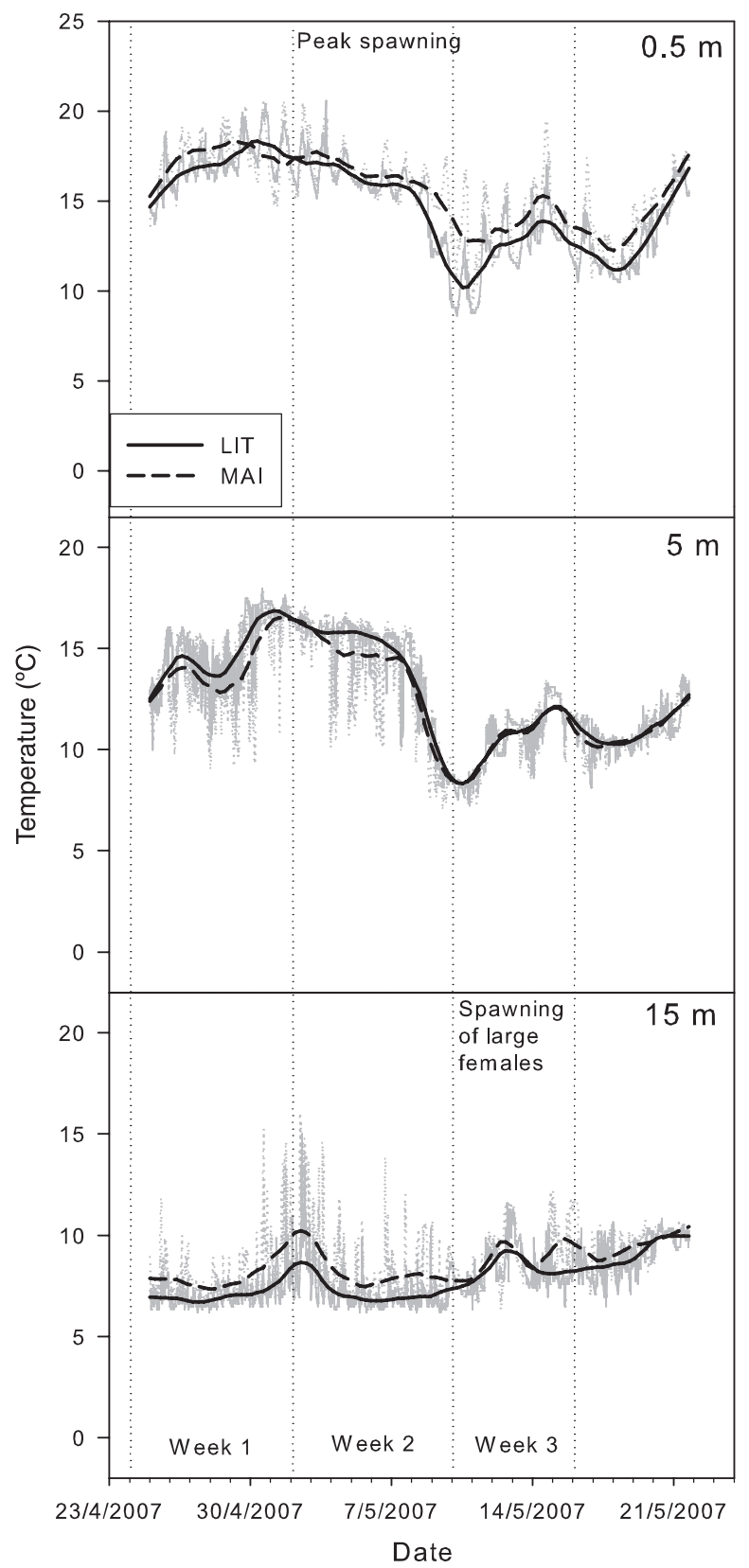

Fig. 2. Water temperatures at $0.5,5$ and $15 \mathrm{~m}$ depth at the experimental sites LIT (straight lines) and MAI (dashed lines) between 25 April and 24 May 2007. Black lines are spline lines of the running $10 \%$ average mean, grey lines are plots of raw data measured at 15-min intervals. Dotted lines indicate the period of peak spawning and the period of large female spawning.

tures at $15 \mathrm{~m}$ depth increased steadily. However, if water temperature was the main determinant of spawning site selection, why would larger females not come to the shallower areas preferred by their smaller conspecifics? It may be argued that larger females find advantages to deeper spawning habitats that are not related to temperature and delay their spawning until adequate temperatures are reached at their preferred depth. Likely environmental influences 

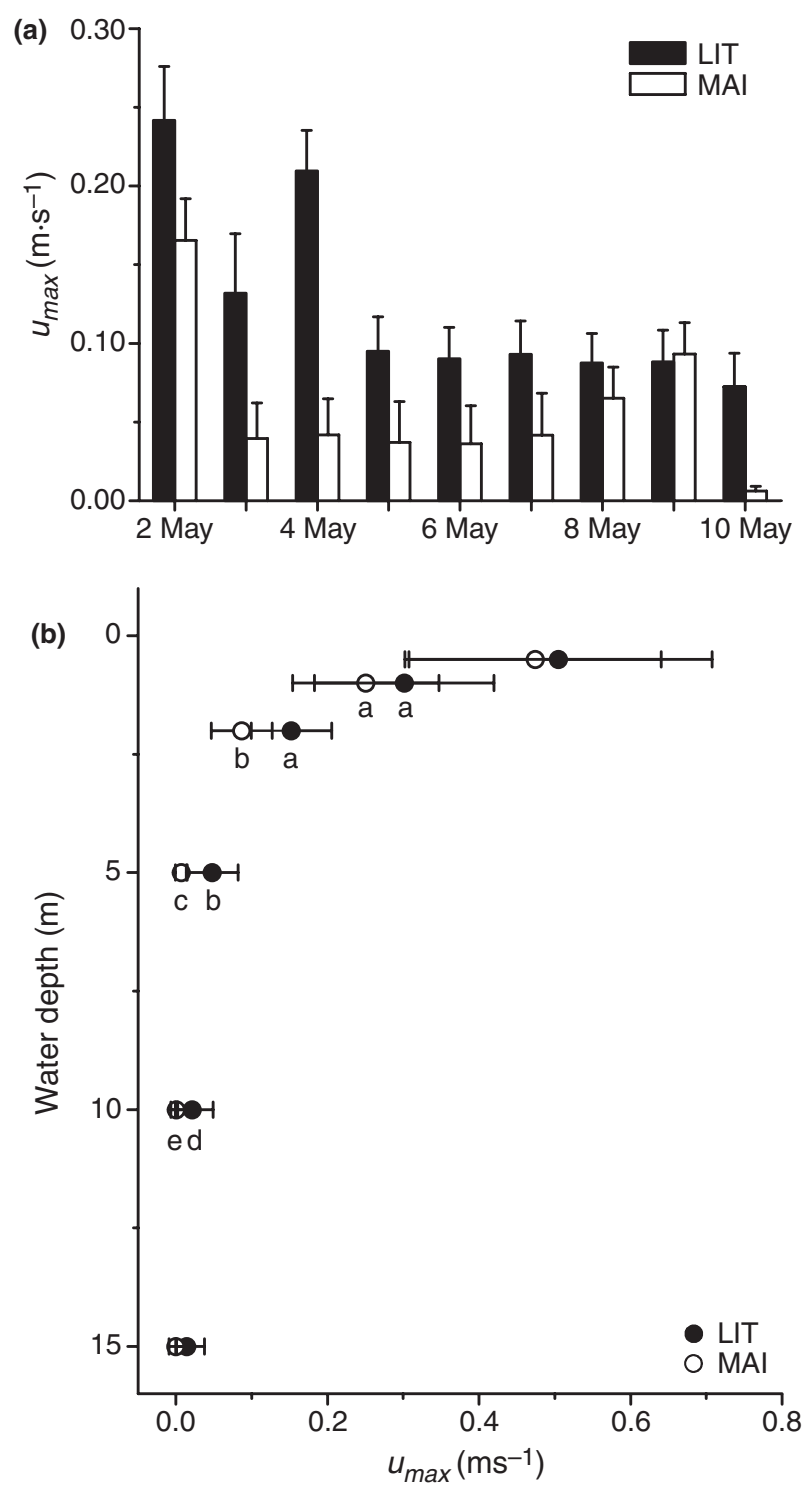

Fig. 3. Wave exposure at the experimental sites LIT and MAI during the peak spawning of perch (week 2). (a) Daily mean values of the upper $10 \%$ of wave-generated maximum near-bottom current velocities, $u_{\max }( \pm \mathrm{SD})$ at $2 \mathrm{~m}$ depth. (b) Overall mean values of the upper $10 \%$ of occurring wave-generated $u_{\max }( \pm \mathrm{SD})$ at the sampling depths of $0.5,1,2,5,10$ and $15 \mathrm{~m}$. The letters indicate homogenous groups calculated by Student-Newman-Keuls test for daily mean $u_{\max }$.

may be the avoidance of UV-radiation and reduced wave exposure.

UV-radiation has been shown to cause severe damage to eggs of yellow perch Perca flavescens and has an influence on spawning depth in lakes with varying water clarity (Williamson et al. 1997; Huff et al. 2004). However, as it is unlikely that the eggs of large female Eurasian perch should be more susceptible to UV-radiation than the eggs of smaller conspecifics, UV avoidance cannot explain the different depth preferences exhibited by perch of different sizes.
Furthermore, water turbidity at LIT was usually higher than at MAI (Probst, personal observation). If UVradiation was a factor in spawning depth selection of perch, the main spawning depth should have been deeper at MAI than at LIT, because turbidity reduces the penetration depth of UV (Huff et al. 2004). However, the opposite pattern was observed making UV-radiation an unlikely factor in the depth distribution of perch egg ribbons in our study.

While temperature and UV-radiation do not explain the differences observed in spawning depth and the relative abundances of large egg ribbons $(>5 \mathrm{~cm})$ between the two experiment sites, the influence of hydrodynamics may account for several aspects of the present results. The main spawning zone was deeper at the more wave-exposed site LIT than at the sheltered site MAI. The impact of surface waves in terms of $u_{\max }$ decreases with depth and thus perch may be compensating for the greater hydrodynamic stress at LIT by depositing the eggs on deeper substrata. This seems plausible and may also explain the different depth preferences or large females favouring deep spawning sites, because their egg ribbons are more affected by wave-generated currents than small ribbons. This would further explain the greater number of large egg ribbons at the sheltered site MAI, which large females may prefer due to lower wave exposure.

Hydrodynamic stress may impact egg ribbons of perch directly by disrupting the egg ribbon via shear forces, or indirectly by smothering the egg ribbons with resuspended particles, causing mortality by oxygen deprivation. Disrupted egg ribbons may become detached from their substratum and be washed ashore (Clady \& Hutchinson 1975) or drop to the lake bottom and die (Smith et al. 2001). The attachment of eggs to the substratum of calm, sheltered waters seems to be crucial in the reproductive success of perch, which may select spawning sites not only based on temperature and substrate structure, but also with respect to wave exposure.

\section{Acknowledgements}

The work for this project was conducted as part of the collaborate research centre CRC 454 'The Littoral zone of Lake Constance'. Jochen Seidel donated as many spruces as our car could carry across the rolling hills of BadenWürttemberg. We further thank Alfred Sulger (tenant of fishery permission at both study sites), Jörg Bambusch (City administration of Konstanz, Department of Urban Development and Environment) and Heinrich Straub (Mainau GmbH) for the permission to set up our experiment. The research dive group from the University of Konstanz deployed and recovered the spruce trunks and counted the perch egg ribbons. Four reviewers provided valuable comments on an earlier version of this manuscript and Amy-Jane Beer improved language and style. 


\section{References}

Aalto, S.K. \& Newsome, G.E. 1993. Winds and the demic structure of a population of yellow perch (Perca flavescens). Canadian Journal of Fisheries \& Aquatic Sciences 50: 496501.

Brown, E., Colling, A., Park, D., J., P., Rothery, D. \& Wright, J. 2005. Waves, tides and shallow-water processes. Butterworth-Heinemann, Oxford.

Clady, M. \& Hutchinson, B. 1975. Effect of high winds on eggs of Yellow perch, Perca flavescens, in Oneida Lake, New York. Transactions of the American Fisheries Society 104: 524-525.

Fischer, P. \& Eckmann, R. 1997. Spatial distribution of littoral fish species in a large European lake, Lake Constance, Germany. Archiv für Hydrobiologie 140: 91-116.

Gafny, S., Gasith, A. \& Goren, M. 1992. Effect of water level fluctuation on shore spawning of Mirogrex terraesanctae (Steinitz), (Cyprinidae) in Lake Kineret, Israel. Journal of Fish Biology 41: 863-871.

Gerstmeier, R. \& Romig, T. 2003. Die Süßwasserfische Europas. Stuttgart: Kosmos.

Gillet, C. \& Dubois, J.-P. 2007. Effect of water temperature and size of females on the timing of spawning of perch Perca fluviatilis L. in Lake Geneva from 1984 to 2003. Journal of Fish Biology 70: 1001-1014.

Gillet, C., Dubois, J.-P. \& Bonnet, S. 1995. Influence of temperature and size of females on the timing of spawning of perch, Perca fluviatilis, in Lake Geneva from 1984 to 1993. Environmental Biology of Fishes 42: 355-363.

Hofmann, H., Lorke, A. \& Peeters, F. 2008. The relative importance of wind and ship waves in the littoral zone of a large lake. Limnology \& Oceanography 53: 368-380.

Huff, D.D., Grad, G. \& Williamson, C. 2004. Environmental constraints on spawning depth of Yellow perch: the roles of low temperature and high solar ultraviolet radiation. Transactions of the American Fisheries Society 133: 718-726.

Kundu, P.K. \& Cohen, I.M. 2008. Fluid mechanics. Oxford: Elsevier.

Rupp, R.S. 1965. Shore-spawning and survival of eggs of American Smelt. Transactions of the American Fisheries Society 94: 160-168.

Sandström, O., Abrahamsson, I., Andersson, J. \& Vetemaa, M. 1997. Temperature effects on spawning and egg development in Eurasian perch. Journal of Fish Biology 51: 10151024.

Smith, C., Douglas, A. \& Jurajda, P. 2001. Oviposition site selection and embryo mortality in perch. Journal of Fish Biology 58: 880-882.

Stoll, S., Fischer, P., Klahold, P., Scheifhacken, N., Hofmann, H. \& Rothhaupt, K.-O. 2008. Effects of water depth and hydrodynamics on the growth and distribution of juvenile cyprinids in the littoral zone of a large pre-alpine lake. Journal of Fish Biology 72: 1001-1022.

Treasurer, J.W. 1988. The distribution and growth of lacustrine 0+ perch, Perca fluviatilis. Environmental Biology of Fishes 21: $37-44$.

Wang, N. 1994. On the ecology of age-0 perch (Perca fluviatilis L.) in Lake Constance. Dissertation. Konstanz: Universität Konstanz.. 104 pp.

Wang, N. \& Eckmann, R. 1994. Distribution of perch (Perca fluviatilis) during their first year of life in Lake Constance. Hydrobiologia 277: 135-143.

Williamson, C.E., Metzgar, S.L., Lovera, P.A. \& Moeller, R.E. 1997. Solar ultraviolet radiation and the spawning habitat of Yellow perch Perca flavescens. Ecological Applications 7: 1017-1023.

Winfield, I.J. 2004. Fish in the littoral zone: ecology, threats and management. Limnologica 34: 124-131. 